\title{
FAKTOR-FAKTOR YANG BERHUBUNGAN DENGAN PENDOKUMENTASIAN DIAGNOSA KEPERAWATAN
}

\author{
Muhaini Atmayana Purba / 181101131
}

muhainipurba21@gmail.com

\begin{abstract}
ABSTRAK
Latar belakang : Kelengkapan pendokumentasian asuhan keperawatan merupakan bagian dari kualitas pelayanan keperawatan di rumah sakit, juga pelaksanaan pendokumentasian adalah indikator kinerja perawat yang dipengaruhi oleh karakteristik dan beban kerja perawat. Tujuan : Tujuan penulisan ini yaitu mengidenifikasi faktor-faktor yang berhubungan dengan pendokumentasian diagnosa keperawatan. Metode : Metode yang digunakan merupakan literatur review atau suatu perbandingan atau analisis antara satu jurnal dengan jurnal lainnya dari berbagai sumber seperti referensi jurnal, buku teks dan e-book. Hasil : Faktor yang paling dominan memengaruhi kelengkapan pendokumentasian adalah pelatihan dan beban kerja. Ada hubungan antara masa kerja, pelatihan dan beban kerja dengan kelengkapan pendokumentasian. Direkomendasikan untuk pelatihan pendokumentasian bagi perawat dan meninjau ulang jumlah perawat serta penempatan tenaga sesuai dengan beban kerja di ruangan. Kesimpulan : Beban kerja perawat pada penelitian ini sebagian besar tinggi dan sebagian besar pendokumentasian yang dilakukan oleh perawat belum lengkap. Berdasarkan karakteristik perawat menunjukkan bahwa umur tidak ada hubungan dengan keleng-kapan pendokumentasian asuhan keperawatan, berbeda halnya dengan masa kerja dan pelatihan menunjukkan ada hubungan yang bermakna dengan kelengkapan pendokumentasian.
\end{abstract}

Kata Kunci : Faktor-faktor, pendokumentasian. Diagnosa, keperawatan

\begin{abstract}
Background : Completeness of documentation of nursing care is part of the quality of nursing services at the hospital, also the implementation of documentation is an indicator of nurse performance that is influenced by nurses' characteristics and workload. Purpose : The purpose of this paper is to identify factors related to documenting nursing diagnoses. Method : The method used is a literature review or a comparison or analysis of one journal with other journals from various sources such as journal references, textbooks and e-books. Results : The most dominant factors affecting the completeness of documentation were training and workload. There is a relationship between tenure, training and workload with complete documentation. Recommended for training documentation for nurses and reviewing the number of nurses and the placement of personnel in accordance with the workload in the room. Conclusion : The workload of nurses in this study was mostly high and most of the documentation done by nurses was incomplete. Based on the characteristics of nurses shows that age has no relationship with the completeness of documentation of nursing care, in contrast to the length of service and training shows that there is a significant relationship with the completeness of documentation.
\end{abstract}

Keywords : Factors, documentation. Nursing diagnoses 


\section{Latar Belakang}

Pendokumentasian merupakan bukti legal pelaksanaan pelayanan di rumah sakit. Kualitas pelayanan disuatu rumah sakit salah satunya dapat dilihat dari pelaksanaan pendokumentasian asuhan keperawatan (Wang, Hailey, \& $\mathrm{Yu}, 2011)$. Pendokumentasian asuhan keperawatan dilakukan sebagai bukti tindakan keperawatan sudah dilakukan secara professional dan legal sehingga dapat memberikan perlindungan pada perawat dan pasien (Iyer \& Camp, 2005). Pendokumentasian berguna bagi rumah sakit dalam meningkatkan standar akreditasi, sebagai alat komunikasi antar profesi, indikator pelayanan mutu, bukti tanggung jawab, dan tanggung gugat perawat, sumber data dan sebagai sarana penelitian (Teytelman, 2002; Jefferies, Johnson, Nicholls \& Lad, 2012).

Dokumentasi secara umum merupakan suatu catatan otentik atau semua warkat asli yang dapat dibuktikan atau dijadikan bukti dalam persoalan hukum. Dokumentasi keperawatan merupakan bukti pencatatan dan pelaporan yang dimiliki perawat dalam melakukan catatan keperawatan yang berguna untuk kepentingan klien, perawat dan tim kesehatan dalam memberikan pelayanan kesehatan dengan dasar komunikasi yang akurat dan baik secara tertulis dengan tanggung jawab perawat (Hidayat, 2007).

Pendokumentasian asuhan keperawatan adalah proses pelaksanaan pencatatan asuhan keperawatan yakni dari pengkajian saat masuk sampai pasien dinyatakan sehat. Diagnosis yang diangkat berdasarkan masalah yang ditemukan, perencanaan keperawatan, tindakan yang dilakukan serta evaluasi dari proses asuhan keperawatan yang diberikan (Nursalam, 2007).

Pendokumentasian yang tidak lengkap akan memberikan kerugian bagi klien karena infor-masi penting terkait perawatan dan kondisi kesehatannya terabaikan (Teytelman, 2002). Braaf, Manias dan Riley (2011) menjelaskan bahwa pendokumentasian yang tidak efisien dan tidak efektif akibat dari kualitas dan ke-akuratannya kurang memadai menyebabkan terjadinya kesalahan komunikasi antar perawat maupun profesi lain. Komisi keselamatan perawatan dan kualitas kesehatan Australia pada 2008 mengidentifikasi $13 \%$ dari kesalahan manajemen klinis berasal dari kesalahan 
dokumentasi (Jefferies, Johnson,

Nicholls \& Lad, 2012).

\section{Tujuan}

Tujuan penulisan ini yaitu mengidenifikasi faktor-faktor yang berhubungan dengan pendokumentasian diagnosa keperawatan.

\section{Metode}

Metode yang digunakan merupakan literatur review atau suatu perbandingan atau analisis antara satu jurnal dengan jurnal lainnya dari berbagai sumber seperti referensi jurnal, buku teks dan e-book.

\section{Hasil \& Pembahasan}

Dari hasil analisis multivariat didapatkan sikap berhubungan sebab akibat dengan

perilaku pendokumentasian asuhan keperawatan di RSJ Tampan Pekanbaru. Menurut Green dalam Notoatmodjo (2010) mengatakan bahwa sikap menentukan perilaku seseorang. Sikap yang positif diharapkan menjadi dorongan yang kuat dalam usaha melakukan pendokumentasian asuhan keperawatan. Kekuatan hubungan antara sikap perawat dengan pendokumentasian asuhan keperawatan dapat dilihat dari nilai POR yang diperoleh sebesar 7.770 (CI 95\%: 1.274-6.920). Artinya perawat dengan sikap positif berpeluang 8 kali untuk melakukan pendokumentasian asuhan keperawatan Baik dari perawat yang memiliki sikap negatif. Hasil penelitian ini konsistensi dengan penelitian Mastini (2013) dan Dewi (2004), bahwa adanya hubungan signifikan antara sikap dengan pendokumentasian asuhan keperawatan.

Dari implikasi model pada hasil didapatkan bahwa perawat yang memiliki sikap yang negatif, perilakunya untuk pendokumentasian asuhan keperawatan kurang baik. Pengetahuan, insentif dan beban kerja adalah counfounding terhadap sikap. Pengetahuan yang kurang pada perawat berhubungan dengan pendokumentasian yang kurang. Insentif yang kurang berhubungan dengan pendokumentasian kurang. Beban kerja yang tidak sesuai berhubungan dengan pendokumentasian kurang.

Karena itu direkomendasikan supaya pendokumentasian dapat dilakukan dengan baik, maka diperlukan sikap positif. Agar sikap perawat positif diperlukan pengetahuan yang baik, insentif yang cukup dan beban kerja yang sesuai. Sehingga disarankan untuk:

1. Insentif pagi perawat yang melakukan pendokumentasian baik 
belum terealisasi dikarenakan masih terhambat karena pergantian direktur di RSJ, sehingga disarankan pemberian insentif diberikan secara berkala sesuai dengan penilaian/ rapor perawat dalam pendokumentasian asuhan keperawatan yang dilakukan perawat. Pemberian insentif dapat berupa bonus uang jasa, penghargaan perawat teladan, pengiriman pada seminar, pelatihan bagi perawat yang melakukan pendokumentasian asuhan keperawatan dengan baik

2. Pengetahuan perawat yang baik dalam pendokumentasian masih kurang dikarenakan kurangnya penyegaran dan pembinaan mengenai pendokumetasian itu sendiri, sehingga disarankan agar dilakukan penyegaran rutin keperawatan mengenai pendokumentasian dan melakukan pembinaan melalui In House Training guna peningkatan pengetahuan perawat dalam pendokumentasian asuhan keperawatan.

3. Beban kerja yang sesuai di RSJ Tampan pada tiap ruang rawat masih belum terealisasi, hal ini dikarenakan jumlah tenaga perawat yang ada sangat kurang jika dilihat dari jumlah pasien, sehingga didisarankan meningkatkan sumber daya perawat guna mengoptimalkan pelaksanaan pendokumentasian asuhan keperawatan yang baik.

Sejalan dengan penelitian Amril (2004) di RSUD Pariaman dan Dini (2009) di RSJ HB Sa'anin bahwa tidak ada hubungan kepemimpinan dengan perilaku pendokumentaian asuhan keperawatan.

Kepemimpinan tidak menunjukkan ada hubungan yang signifikan dengan perilaku pedokumentasian asuhan keperawatan mungkin juga bisa disebabkan karena kelemahan kuisioner yang kurang kaya membahas mengenai kepemimpinan itu sendiri, serta jumlah sampel yang kecil. Sehingga direkomendasikan untuk peneliti selanjutnya lebih memperkaya jumlah pertanyaan mengenai kepemimpinan dan memilih RS yang memiliki banyak perawat.

Kepemimpinan secara substansi memiliki hubungan dengan perilaku pendokumentasian asuhan keperawatan. Di RSJ Tampan kepemimpinan dalam hal ini kepala ruangan setiap bulannya memberikan laporan berupa rapor bagaimana pendokumentasian yang dilakukan perawat, kepala ruangan lebih memperhatikan nilai kemanusiaan sesama perawat. Dimana jika perawat 
diruangan tidak melakukan pendokumentasian dengan baik maka perawat akan mendapatkan sanksi, sanksi diawali dengan pemanggilan bagian kabid. keperawatan, sampai dengan mutasi pada perawat tersebut. Dengan pertimbangan itulah kepala perawat cenderung memberikan penilaian yang baik kepada perawat.

\section{Kesimpulan \& Saran}

Beban kerja perawat pada penelitian ini sebagian besar tinggi dan sebagian besar pendokumentasian yang dilakukan oleh perawat belum lengkap. Berdasarkan karakteristik perawat menunjukkan bahwa umur tidak ada hubungan dengan keleng-kapan pendokumentasian asuhan keperawatan, berbeda halnya dengan masa kerja dan pelatihan menunjukkan ada hubungan yang bermakna dengan kelengkapan pendokumentasian. Beban kerja juga menunjukkan ada hubungan yang bermakna. Faktor yang paling dominan terhadap kelengkapan pendokumentasian adalah pelatihan dan beban kerja.

Rekomendasi untuk meningkatkan kualitas pelayanan dalam hal kelengkapan pendokumen-tasian asuhan keperawatan adalah meningkatkan frekuensi pengawasan dan penilaian terhadap pelaksanaan pendokumentasian asuhan kepera-watan di rumah sakit. Peningkatan pelatihan terhadap pendokumentasian asuhan keperawatan yang dapat dilakukan secara berkala. Meningkat-kan strategi pengelolaan sumber daya manusia keperawatan dengan meninjau ulang ketenagaan yang tersedia, merekrut tenaga baru untuk mengimbangi kekurangan tenaga akibat beban kerja perawat yang tinggi dan menempatkan SDM sesuai dengan beban kerja yang tersedia di ruangan. Hasil temuan dalam penelitian ini dapat dijadikan referensi yang dapat dijadikan alternatif pengembangan kurikulum manajemen keperawatan pada pendidikan keperawatan dalam meningkatkan solusi untuk memecahkan masalah terkait pelaksanan pendokumentasian asuhan keperawatan yang dikaitkan dengan beban kerja perawat. Peneliti selanjutnya perlu dilakukan penelitian action research atau quasi experiment sehingga dapat diketahui lebih mendalam dan akurat terkait faktorfaktor yang memengaruhi pendokumentasian asuhan keperawatan (RR, ENN). 


\section{Daftar Pustaka}

Amril. (2004). Faktor-Faktor Yang

Berhubungan Dengan Perilaku

Perawat Dalam Melaksanakan

Pendokumentasian Asuhan

Keperawatan Di RSUD Pariaman

2004. Jakarta: Perpustakaan FKM

UI (Tidak dipublikasikan)

Braaf, S., Manias, E., \& Riley, R. (2011). The role of documents and documentation in communication failure across the perioperative pathway: A literature review. International Journal of Nursing Studies, 48 (8), 1024-1038.

doi: 10.1016/j.ijnurstu. 2011.05.009.

Carpenito, Ll. (2007). Diagnosa Keperawatan. Jakarta: EGC

Dahlan, M. (2004). Statistik Untuk Kedokteran dan Kesehatan. Jakarta: Salemba Medika

Duffield, C. (2011). Nursing staffing, nursing workload, the environment and patients outcomes. Applied Nursing Research, 24, 244-255.

Fribeg, F., Bergh, A.L., \& Lepp, M. (2006). In search of details of patient teaching in nursing documentation: An analysis of patient records in a medical ward in Sweden. Journal of Clinical Nursing, 15, 1550-1558.

Ilyas, Y. (2012). Kinerja: Teori, penilaian, dan penelitian (Edisi revisi). Depok: Fakultas Kesehatan Masyarakat UI.

Jefferies, D., Johnson, M., Nicholls, D., \& Lad, S. (2012). A ward-based writing coach program to improve the quality of nursing documentation. Journal Nurse Education Today, 32, 647-651.

Potter, P.A., \& Perry, G.A. (2010). Fundamental of nursing (Volume 2, 7th Ed.). ST. Louis: Mosby Year Book.

Simamora, R. H. (2008). Peran Manajer Perawat Dalam Pembinaan Etika Perawat Pelaksana Dalam Peningkatan Kualitas Asuhan Keperawatan. IKESMA

Simamora, R. H. (2009). Dokumentasi Proses Keperawatan. Jember. University Press

Simamora, R. H. (2010). Komunikasi Dalam Keperawatan. Jember: University Press

Sugiharto, A.S., Keliat, B.A., Hariyati, T.S. (2012). Manajemen keperawatan aplikasi MPKP di rumah sakit. Jakarta: EGC. 
Teytelman, Y. (2002). Effective nursing documentation and communication. Seminars in Oncology Nursing, 18 (2), 121127.

Wang, N., Hailey, D \& Yu, P. (2011). Quality of nursing documentation and approaches to its evaluation: A mixed-method systematic review. Journal of Advanced Nursing, 67 (9), 1858-1875. 